\title{
Risk, Governance, Earnings, Capital (RGEC) Method And Maqashid Sharia Index (MSI) : The Soundness Level Of Islamic Banks In Indonesia
}

\author{
$1^{\text {st }}$ Aulia Octaviana $\mathrm{D}^{1}, 2^{\text {nd }}$ Fitri Indriawati ${ }^{2}$ \\ \{auliaoctaviana@gmail.com ${ }^{1}$,fitri_indriawati@mercubuana.ac.id ${ }^{2}$ \} \\ Universitas Mercu Buana, Jakarta ${ }^{12}$
}

\begin{abstract}
The purpose of this study is to analyze the soundness level the Islamic Banks in Indonesia by using the Risk, Governance, Earnings, Capital (RGEC) and Maqashid Sharia Index (MSI) approaches in 2013-2017 and to know the importance of using MSI in completing bank performance assessment. The research method used is descriptive research with a quantitative approach. This research using 6 samples of public Islamic Banks (BUS) namely BMI, BRIS, BSM, BNIS, BMS and BCAS. The RGEC aspect uses Comparative Performance Index (CPI) measurements and the Maqashid Sharia aspect uses MSI measurements and then compared both using Cartesian diagram. The result proves that the soundness of the bank as measured by the RGEC method shows a different ranking sequence with the Maqashid Sharia Index method. The order of bank soundness ratings based on RGEC is BCAS, BMS, BNIS, BRIS, BSM and BMI while based on Maqashid Sharia Index (MSI) the ranks first to last is BCAS, BMI, BRIS, BNIS, BSM and BMS. Both methods can be used simultaneously to assess the soundness level in Islamic banking because both methods can complement each other in order to obtain a more comprehensive assessment.
\end{abstract}

Keywords: RGEC, Maqashid Sharia Index, CPI, Soundness Level

\section{Pendahuluan}

Perbankan syariah memiliki kriteria khusus berdasarkan tujuan maqashid syariah sehingga dalam menilai tingkat kesehatan bank syariah harus dilakukan dengan cara yang berbeda dari bank konvensional. Namun pada kenyataannya tingkat kesehatan perbankan syariah di Indonesia masih dinilai dengan menggunakan cara yang sama seperti pada bank konvensional sesuai ketetapan Bank Indonesia dan Otoritas Jasa Keuangan yaitu CAMEL (Capital, Asset, Management, Earning, Liquidity, Sensitivy of Market Risk) dan EVA (Ecconomic Value Added) serta yang terakhir diatur dalam POJK Nomor 8/POJK.03/2014 yaitu RGEC (Risk, Governance, Earnings, Capital) maka penilaian tersebut masih kurang mewakili kondisi dari perbankan syariah itu sendiri. Sehingga terlihat seolah-olah perbankan syariah tujuannya berfokus pada keuntungan semata (profit oriented) dan sangat sedikit bahkan tidak mengandung tujuan sosial (1). Maqashid syariah wajib diterapkan oleh setiap lembaga yang berbasis syariah dan pemerintah, tetapi hingga kini masih sangat kurang penilaian kinerja berbasis maqashid syariah yang dilakukan terhadap lembaga berbasis syariah termasuk bank syariah $(2)(3)(4)(5)(6)$, maka penting untuk menganalisis tingkat kesehatan perbankan syariah yang dilakukan dengan berdasarkan pada maqashid syariah. 
Muhammed (2008) dalam risetnya menghasilkan pengukuran kinerja dalam bentuk Shariah Maqashid Index (SMI) (2),(7). Riset ini mengukur Maqashid syariah berdasarkan pada konsep maqashid syariah dari Abu Zahrah (1958)(8) yaitu terkait dengan tiga tujuan dari tegaknya hukum Islam sebagai berikut : Tahzin al-Fardi (Terdidiknya Manusia), Iqamah al-Adl (Penegakkan Keadilan) dan Jalb al-Maslahah (Terciptanya Kebermanfaatan). Indikator pengukuran dibuat berdasarkan tiga aspek tersebut. Penelitian memiliki tujuan ini membandingkan performa perbankan syariah yang diukur berdasarkan metode RGEC dengan indeks Maqashid Syari'ah (MSI) dan peran MSI dalam melengkapi penilaian kinerja perbankan syariah.

\section{Kajian Pustaka}

\subsection{Metode RGEC}

Menurut POJK No. 8/POJK.3/2014 metode RGEC berkaitan dengan beberapa risiko berikut:

a. Profil Risiko (Risk Profile)

Berkaitan dengan asesmen terkait risiko bawaan dan kualitas penerapan Manajemen Risiko dalam aktivitas rutin bank.

1) Risiko Kredit

Risiko ini diukur dengan rumus:

2) Risiko Pasar

$$
\text { NPF }=\frac{\text { Kredit Bermasalah }}{\text { Total Kredit }} X 100 \%
$$

3) Risiko Likuiditas, menggunakan FDR

4) Risiko Operasional

5) Risiko Hukum

6) Risiko Stratejik

7) Risiko Kepatuhan

8) Risiko Reputasi

9) Risiko Imbal Hasil

10) Risiko Investasi

b. Nilai komposit GCG (penilaian mandiri) .

c. Earnings (Rentabilitas)

$$
\begin{aligned}
& \text { ROA }=\frac{\text { Laba sebelum pajak }}{\text { Rata-rata total aset }} X 100 \% \\
& \text { BOPO }=\frac{\text { Beban Operasional }}{\text { Pendapatan Operasional }} X 100 \%
\end{aligned}
$$

d. Capital, menggunakan CAR 
pengukuran RGEC melalui dua langkah, yaitu:

1. Menentukan rasio RGEC rata-rata.

2. Melakukan pemeringkatan bank berdasarkan metode Comparative Performance Index (CPI) (9).

Proses pengambilan keputusan dengan banyak kriteria di mana arah, rentang dan besaran masing-masing kriteria tidak sama dapat diselesaikan dengan CPI yaitu dengan mengubah matriks keputusan ke dalam bentuk yang seragam Xij diubah menjadi Aij dengan :

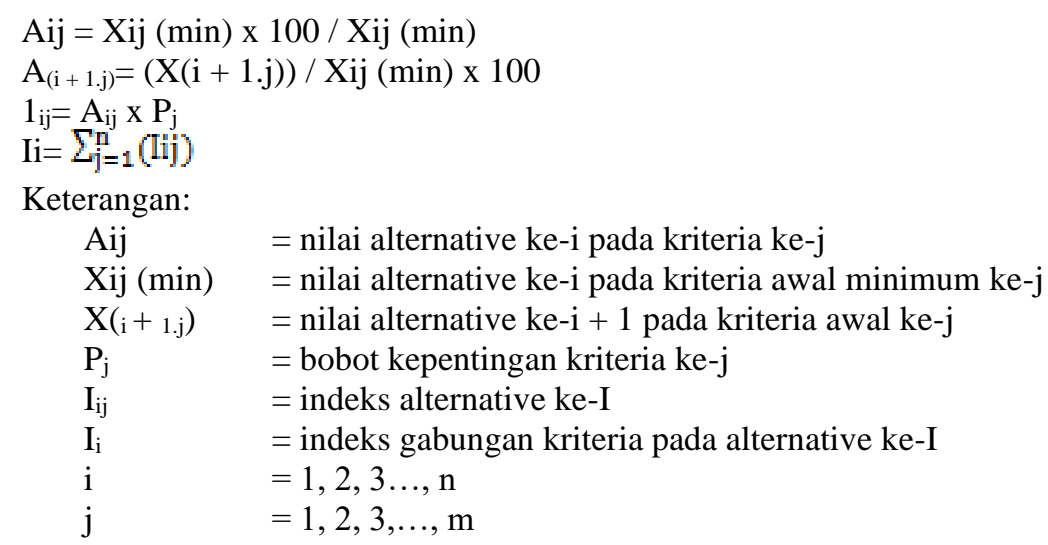

Prosedur Penyelesaian CPI adalah sebagai berikut:

a. Identifikasi kriteria tren positif dan tren negatif

b. Untuk tren positif, nilai minimum pada setiap kriteria ditranformasikan ke seratus, sedangkan nilai lainnya ditransformasi secara proporsional lebih tinggi.

Untuk tren negatif, nilai minimum pada setiap kriteria ditransformasi ke seratus, sedangkan nilai lainnya di transformasi secara proporsional lebih rendah

\subsection{Maqashid Syari’ah}

Maqashid syari'ah secara bahasa terdiri dari dua kata berikut : maqashid dan syari'ah. Maqashid merupakan bentuk jamak dari maqshud yang artinya tujuan. Sementara syari'ah artinya jalan menuju air, atau bisa dikatakan dengan jalan ke arah sumber kehidupan (10). Maqashid syari'ah dibuat oleh Allah dalam rangka memberikan kemaslahatan kepada manusia sehingga kebutuhan dlaruriyah, hajiyah dan tahsiniyah terpenuhi dan kehidupan manusia menjadi sejahtera serta menjadi hamba Allah yang baik.

Terpenuhinya kemaslahatan manusia sebagai makhluk sosial merupakan tujuan dari maqashid syari'ah di mana dia memiliki tanggung jawab pada diri sendiri dan saat akhir nanti pada Allah dia harus mempertanggungjawabkan semuanya (10)

\subsection{Maqashid Syari'ah Index}

Mohammed dkk (2008) telah mengembangkan indeks Maqashid syari'ah untuk menilai performa sesuai dengan karakteristik perbankan syari'ah dengan berbasis pada teori maqashid syariah Abu Zahrah (11). Mohammed, dkk (2008) menggunakan metode Sekaran (2000) yang memerinci konsep maqasid syariah Abu Zahrah menjadi beberapa dimensi dalam bentuk 
perilaku yang bisa diobservasi (10). Setelah itu setiap dimensi dipecah menjadi beberapa elemen yang dapat diukur dengan rasio keuangan bank syariah.

Tabel 1. Operasional Tujuan Bank Syariah

\begin{tabular}{|c|c|c|c|}
\hline $\begin{array}{l}\text { Konsep } \\
\text { (Tujuan) }\end{array}$ & Dimensi & Elemen & Rasio Kinerja \\
\hline \multirow{4}{*}{$\begin{array}{l}\text { 1. Tahzib al- } \\
\text { Fard } \\
\text { (Mendidik } \\
\text { Individu) }\end{array}$} & \multirow[t]{2}{*}{$\begin{array}{l}\text { D1. Memajukan } \\
\text { Pengetahuan }\end{array}$} & $\begin{array}{l}\text { E1. Bantuan } \\
\text { Pendidikan }\end{array}$ & $\begin{array}{c}\text { R1. Bantuan } \\
\text { Pendidikan/Total Beban } \\
\end{array}$ \\
\hline & & E2. Penelitian & $\begin{array}{l}\text { R2. Beban Penelitian/Total } \\
\text { Beban }\end{array}$ \\
\hline & $\begin{array}{l}\text { D2. Menerapkan dan } \\
\text { Meningkatkan Keahlian } \\
\text { Baru }\end{array}$ & E3. Pelatihan & $\begin{array}{l}\text { R3. Beban Pelatihan/Total } \\
\text { Beban }\end{array}$ \\
\hline & $\begin{array}{c}\text { D3. Menciptakan } \\
\text { Kesadaran akan Bank } \\
\text { Syariah } \\
\end{array}$ & E4. Publikasi & $\begin{array}{l}\text { R4. Beban Promosi/Total } \\
\text { Beban }\end{array}$ \\
\hline \multirow{3}{*}{$\begin{array}{l}\text { 2. Iqamah al- } \\
\text { Adl } \\
\text { (Menegakkan } \\
\text { Keadilan) }\end{array}$} & D4. Pengambilan yang adil & $\begin{array}{l}\text { E5. Return yang } \\
\text { adil }\end{array}$ & R5. Laba/Total Pendapatan \\
\hline & $\begin{array}{l}\text { D5. Produk dan pelayanan } \\
\text { yang terjangkau }\end{array}$ & $\begin{array}{c}\text { E6. Fungsi } \\
\text { Distribusi }\end{array}$ & $\begin{array}{l}\text { R6. Pembiayaan Mudharabah } \\
\text { \& Musyarakah/Total } \\
\text { Pembiayaan } \\
\end{array}$ \\
\hline & $\begin{array}{l}\text { D6. Dihilangkannya unsur- } \\
\text { unsur negatif yang bisa } \\
\text { menyebabkan hilangnya } \\
\text { keadilan }\end{array}$ & $\begin{array}{l}\text { E7. Produk Bebas } \\
\text { Bunga }\end{array}$ & $\begin{array}{c}\text { R7. Penghasilan bebas } \\
\text { bunga/Total Penghasilan }\end{array}$ \\
\hline \multirow{3}{*}{$\begin{array}{l}\text { 3. Jalb al- } \\
\text { Maslaha } \\
\text { Memelihara } \\
\text { Kemaslahatan }\end{array}$} & D7. Profitabilitas Bank & E8. Rasio Laba & R8. Laba bersih/Total Aset \\
\hline & $\begin{array}{l}\text { D8. Redistribusi } \\
\text { Pendapatan \& } \\
\text { Kesejahteraan }\end{array}$ & $\begin{array}{l}\text { E9. Pendapatan } \\
\text { Individu }\end{array}$ & $\begin{array}{c}\text { R9. Zakat yang } \\
\text { dibayarkan/Aset Bersih }\end{array}$ \\
\hline & D9. Investasi di sektor riil & $\begin{array}{c}\text { E10. Rasio } \\
\text { Investasi di Sektor } \\
\text { Riil }\end{array}$ & $\begin{array}{l}\text { R10. Investasi Sektor } \\
\text { Riil/Total Investasi }\end{array}$ \\
\hline
\end{tabular}

Sumber: (10)

\section{Pengukuran Kinerja dengan Maqashid Syariah Index}

Pengukuran kinerja maqashid syari'ah bank syariah melalui tiga langkah, yaitu:

1. Menghitung sepuluh rasio kinerja maqashid syari'ah

2. Melakukan pemeringkatan berdasarkan Indikator Kinerja (IK).

3. Menetapkan Indeks Maqashid Syariah (IMS)/Maqashid Syariah Index (SMI

Maqashid Syariah Index (MSI) untuk setiap bank syariah merupakan total semua kinerja indikator dari 3 tujuan maqasid syariah, maka MSI masing-masing bank syariah dapat ditentukan sebagai berikut:

$\mathrm{IMS}=\mathrm{IK}(\mathrm{T} 1)+\mathrm{IK}(\mathrm{T} 2)+\mathrm{IK}(\mathrm{T} 3)$ 


\section{Metode Penelitian}

\subsection{Desain Penelitian}

Penelitian ini adalah penelitian deskriptif dengan pendekatan kuantitatif dan kualitatif, memberikan gambaran secara sistematis dan akurat yang membandingkan kinerja perbankan syariah yang diukur dengan metode RGEC dengan kinerja yang berbasis Maqashid Syariah.

\subsection{Populasi dan Sampel Penelitian}

Bank Umum Syariah di Indonesia periode 2013 - 2017 merupakan populasi dari penelitian kami dengan sampel yang dipilih menggunakan kriteria perusahaan yang melaporkan laba dan melaporkan Good Corporate Governance sehingga terpilih 6 (enam) bank umum syariah yaitu : Bank Muamalat Indonesia, BRI Syariah, Bank Syariah Mandiri, BNI Syariah, Bank Mega Syariah, dan Bank Mega Syariah (12)(13)(14)(15)(16)(17).

\subsection{Metode Analisis Data}

Data dianalisis dengan metode deskriptif kuantitatif dan kualitatif. Setelah mendapatkan hasil perhitungan tingkat kesehatan perbankan syariah dari metode RGEC dan Maqashid Syari'ah Index kemudian digunakanlah diagram kartesius untuk membandingkan kedua pengukuran tersebut (2).Tahapan analisis sebagai berikut :

1. Menetapkan rata-rata nilai tingkat kesehatan (RGEC) dan maqashid syari'ah index.

2. Menempatkan rata-rata nilai setiap aspek ke dalam diagram kartesius. Sumbu Y untuk tingkat kesehatan dan Sumbu X untuk tingkat Maqashid Syariah dengan ketentuan berikut ini:

$$
\begin{aligned}
& \bar{x}=\frac{\sum x i}{\mathrm{n}} \\
& \bar{y}=\frac{\sum y i}{\mathrm{n}}
\end{aligned}
$$

$$
\begin{aligned}
& \text { Keterangan: } \\
& \begin{aligned}
\bar{x} & =\text { skor rata-rata Maqashid Syari'ah Index } \\
\bar{y} & =\text { skor rata-rata tingkat kesehatan bank syariah } \\
\mathrm{xi} & =\text { total skor setiap tingkat Maqashid Syari'ah Index semua sampel } \\
\text { yi } & =\text { total skor untuk tingkat kesehatan dari semua sampel } \\
\mathrm{n} & =\text { total sampel }
\end{aligned}
\end{aligned}
$$




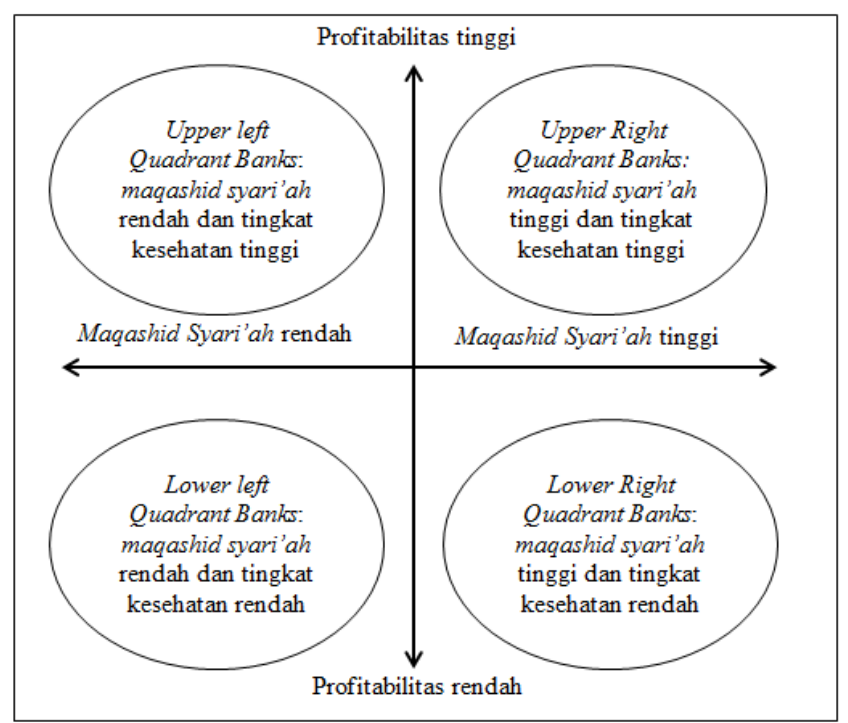

Sumber: Afrinaldi (2013)

Gambar 1. Diagram Kartesius Kinerja Profitabilitas dan Maqashid Syariah Perbankan Syariah di Indonesia [1]

\section{Analisa Hasil dan Pembahasan}

Pemeringkatan bank syariah pada penelitian ini menggunakan metode Comparative Performance Index (CPI) untuk kemudian dilakukan komparasi dengan performa maqashid syari'ah yang tercermin dalam Maqashid Syari'ah Index (MSI).

Dari tabel 2 dapat dilihat bahwa BCA Syariah memiliki nilai CPI terbaik yaitu sebesar 174,06 dan diikuti oleh Bank Mega Syariah, BNI Syariah, BRI Syariah, Bank Syariah Mandiri, dan terakhir ditempati oleh Bank Muamalat Indonesia.

\subsection{Maqashid Syari'ah Index}

Penilaian kinerja dengan MSI dilakukan ke dalam 3 (tiga) langkah, yaitu: menghitung setiap rasio kinerja maqashid syari'ah, melakukan pemeringkatan berdasarkan indikator kinerja (IK), dan menentukan MSI setiap bank syariah. Berikut ini adalah analisis hasil MSI:

\section{a. Tujuan 1. Mendidik Individu (Tahzib al Fard)}

Bank Syariah Mandiri lebih baik dalam memberi bantuan pendidikan. Terkait penelitian dan pengembangan Bank Muamalat Indonesia lebih unggul. Sedangkan BNI Syariah lebih bagus dilihat dari pelaksanaan pelatihan kepada karyawannya dan dalam melaksanakan publikasi atau promosi kepada masyarakat.

Tabel 2. Peringkat Kinerja Bank Syariah

\begin{tabular}{|c|c|c|c|c|c|c|c|c|}
\hline \multirow{2}{*}{ Bank } & \multicolumn{6}{|c|}{ Kriteria CPI } & \multirow{2}{*}{$\begin{array}{c}\text { Nilai } \\
\text { Altern } \\
\text { atif }\end{array}$} & \multirow[b]{2}{*}{ Peringkat } \\
\hline & $\begin{array}{c}\text { NPF } \\
(-)\end{array}$ & $\begin{array}{c}\text { FDR } \\
(-)\end{array}$ & $\begin{array}{c}\text { GCG } \\
(-)\end{array}$ & $\begin{array}{c}\text { ROA } \\
(+)\end{array}$ & $\begin{array}{c}\text { BOP } \\
\text { O }\end{array}$ & $\begin{array}{c}\text { CAR } \\
(+)\end{array}$ & & \\
\hline
\end{tabular}




\begin{tabular}{|c|c|c|c|c|c|c|c|c|}
\hline & & & & & $(-)$ & & & \\
\hline BMI & $\begin{array}{r}* 6,5 \\
0 \\
\end{array}$ & 90,40 & 47,27 & $\begin{array}{r}100,0 \\
0 \\
\end{array}$ & 91,37 & 100,00 & $\begin{array}{r}* * * 72 \\
59\end{array}$ & 6 \\
\hline BRIS & 6,94 & 94,53 & 82,80 & $\begin{array}{r}287,5 \\
0 \\
\end{array}$ & 93,99 & $\begin{array}{r}* * 124,0 \\
6\end{array}$ & 114,97 & 4 \\
\hline BSM & 6,38 & $\begin{array}{r}100,0 \\
0\end{array}$ & 71,04 & $\begin{array}{r}270,8 \\
3\end{array}$ & 94,51 & 107,01 & 108,30 & 5 \\
\hline BNIS & $\begin{array}{r}14,0 \\
5 \\
\end{array}$ & 91,76 & 59,63 & $\begin{array}{r}566,6 \\
7 \\
\end{array}$ & $\begin{array}{r}100,0 \\
0 \\
\end{array}$ & 125,26 & 159,56 & 3 \\
\hline BMS & 9,77 & 86,98 & 78,31 & $\begin{array}{r}591,6 \\
7 \\
\end{array}$ & 96,03 & 145,85 & 168,10 & 2 \\
\hline $\begin{array}{c}\text { BCA } \\
\text { S }\end{array}$ & $\begin{array}{r}100 \\
00\end{array}$ & 92,28 & $\begin{array}{r}100,0 \\
0\end{array}$ & $\begin{array}{r}425,0 \\
0\end{array}$ & 97,20 & 229,86 & 174,06 & 1 \\
\hline Bobot & 0,17 & 0,17 & 0,17 & 0,17 & 0,17 & 0,17 & & \\
\hline
\end{tabular}

Sumber: Data diolah tahun 2018

\section{b. Tujuan ke-2 : Menegakkan Keadilan (Iqamah al Adl)}

BNI Syariah terbukti lebih unggul terkait keadilan pemberian return. Sedangkan BCA Syariah lebih unggul dalam fungsi distribusi dan dalam jumlah pendapatan bebas bunga. Dalam penegakkan keadilan BCA Syariah meraih kinerja yang unggul dibandingkan dengan bank syariah lainnya.

\section{c. Tujuan Ke-3 : Kepentingan Publik (Jalb al Maslahah)}

Berdasarkan tabel indikator kinerja kemaslahatan ummat, BNI Syariah dan Bank Mega Syariah mempunyai kemampulabaan lebih tinggi dari bank syariah lainnya. Performa pembayaran zakat yang bagus diraih oleh BRI Syariah. Sementara BCA Syariah terbaik dalam pemberian pembiayaan di sektor riil dari bank syariah lainnya. Terkait performa pencapaian kebermanfaatan bagi umat BRI Syariah mengumpulkan skor yang lebih tinggi dari bank lain.

Indeks Maqashid Syari'ah Index mengukur semua kinerja pencapaian tiga tujuan syariah. MSI didapatkan dengan menjumlahkan indikator kinerja (IK) bank syariah dari tujuan pertama sampai tujuan ketiga. Berikut ini hasil pemeringkatan maqashid syari'ah bank syariah yang menjadi objek penelitian.

Tabel 3. Maqashid Sharia Index Bank Syariah 2013-2017

\begin{tabular}{|c|l|c|c|c|c|c|}
\hline No & \multicolumn{1}{|c|}{ Bank } & $\begin{array}{c}\text { IK-T1 } \\
(\mathbf{a})\end{array}$ & $\begin{array}{c}\text { IK-T2 } \\
(\mathbf{b})\end{array}$ & $\begin{array}{c}\text { IK-T3 } \\
(\mathbf{c})\end{array}$ & $\begin{array}{c}\text { MSI } \\
{[\mathbf{a + b + c}]}\end{array}$ & Ranking \\
\hline 1 & Bank Muamalat & 0,0029 & 0,2078 & 0,1039 & 0,3146 & 2 \\
\hline 2 & BRI Syariah & 0,0021 & 0,1933 & 0,1180 & 0,3144 & 3 \\
\hline 3 & $\begin{array}{l}\text { Bank Syariah } \\
\text { Mandiri }\end{array}$ & 0,0019 & 0,1741 & 0,1010 & 0,2770 & 5 \\
\hline 4 & BNI Syariah & 0,0048 & 0,1837 & 0,0975 & 0,2860 & 4 \\
\hline 5 & Bank Mega Syariah & 0,0003 & 0,1241 & 0,0999 & 0,2243 & 6 \\
\hline 6 & BCA Syariah & 0,0015 & 0,2252 & 0,1003 & 0,3270 & 1 \\
\hline
\end{tabular}


Berdasarkan tabel hasil maqashid syari'ah index di atas dapat dilihat bahwa pencapaian tertinggi MSI pada tahun 2013 - 2017 adalah BCA Syariah sebesar 0,3270 dengan menduduki peringkat pertama dan diikuti Bank Muamalat Indonesia, BRI Syariah, BNI Syariah, Bank Syariah Mandiri dan Bank Mega Syariah memiliki nilai MSI paling rendah sebesar 0,224.

Tabel 4. Perbandingan RGEC dengan MSI

\begin{tabular}{|l|c|c|r|c|}
\hline \multicolumn{1}{|c|}{ Bank } & MSI & Ranking & $\begin{array}{c}\text { RGEC } \\
(\text { CPI })\end{array}$ & Ranking \\
\hline Bank Muamalat & 0,3146 & 2 & 72,59 & 6 \\
\hline BRI Syariah & 0,3144 & 3 & 114,97 & 4 \\
\hline Bank Syariah Mandiri & 0,2770 & 5 & 108,30 & 5 \\
\hline BNI Syariah & 0,2860 & 4 & 159,56 & 3 \\
\hline Bank Mega Syariah & 0,2243 & 6 & 168,10 & 2 \\
\hline BCA Syariah & 0,3270 & 1 & 174,06 & 1 \\
\hline Nilai Rata-rata & $\mathbf{0 , 2 9 0 6}$ & & $\mathbf{1 3 2 , 9 3}$ & \\
\hline
\end{tabular}

Berdasarkan tabel 4, maka diagram kartesius yang menunjukkan kuadran kinerja terlihat sebagai berikut :

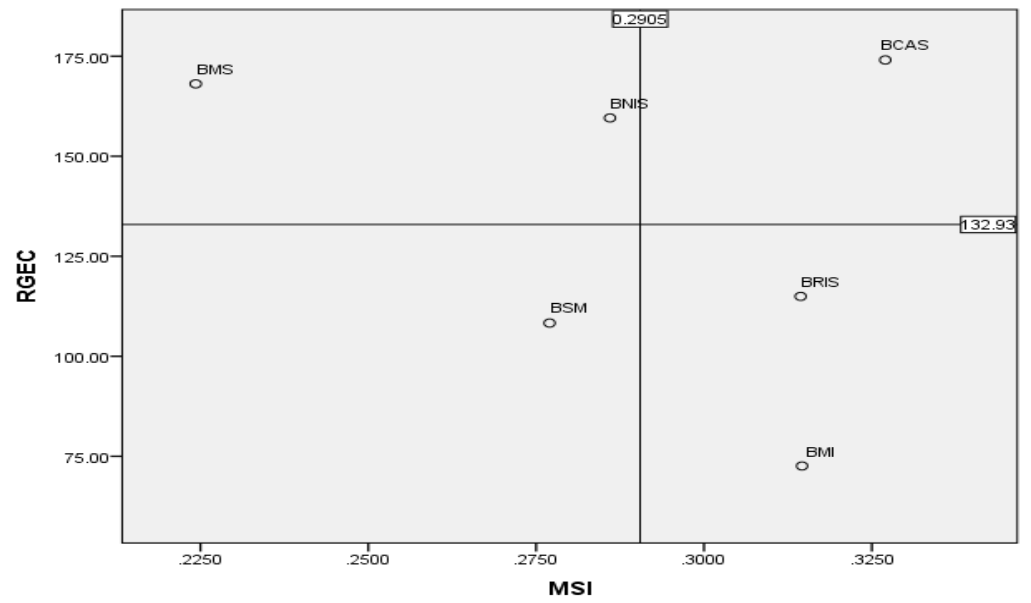

Gambar 2. Diagram Perbandingan RGEC dengan MSI Bank Syariah Periode 2013-2017

\subsection{Pembahasan}

Berikut hasil analisa tingkat kesehatan RGEC dan Maqashid Syari'ah Index per masingmasing kuadran, yaitu:

\section{a. Upper Right Quadrant Banks}

Pada kuadran ini ada bank BCA syariah. Kuadran ini menunjukan pencapaian tingkat kesehatan dengan metode RGEC tertinggi dan pencapaian pelaksanaan maqashid syari'ah yang tertinggi artinya perbankan syariah secara utuh memperhatikan aspek keuangan dan memperhatikan penempatan posisi bank tersebut di masyarakat mengenai aspek syariahnya. 


\section{b. Upper Left Quadrant Banks}

BNI Syariah dan Bank Mega Syariah berada di kuadran ini. Kuadran menunjukkan pencapaian tingkat kesehatan dengan metode RGEC tertinggi dengan pencapaian pelaksanaan maqashid syari'ah terendah artinya bank sangat berfokus terhadap aspek keuangan dibandingkan dengan aspek syariah.

\section{c. Lower Right Quadrant Banks}

BRI Syariah dan Bank Muamalat ada di kuadran ini. Kuadran ini menunjukan pencapaian tingkat kesehatan dengan metode RGEC yang cukup rendah namun kinerja maqashid syari'ah tertinggi. Artinya bank lebih memperhatikan aspek syariah dibandingkan dengan aspek keuangan.

\section{d. Lower Left Quadrant Banks}

Bank Syariah Mandiri (BSM) berada pada kuadran ini. Menunjukkan pencapaian terendah dalam pencapaian tingkat kesehatan dengan metode RGEC dan dalam pelaksanaan maqashid syari'ah.

\subsection{Kesimpulan}

Bank Syariah dengan nilai RGEC tertinggi belum tentu memiliki peringkat tinggi pula berdasarkan Maqashid Sharia Index. Sudah saatnya tingkat kesehatan atau kinerja perbankan syari'ah juga diukur dari sudut penerapan maqashid syari'ah dalam operasional perusahaan bukan hanya dari sudut finansial saja. kedua metode dapat saling melengkapi untuk mendapatkan penilaian yang lebih komprehensif atas kinerja bank syari'ah

\section{References}

1. Mohammad MO, Shahwan S. The Objective of Islamic Economic and Islamic Banking in Light of Maqasid Al-Shariah : A Critical Review. Middle-East J Sci Res. 2013;13(13):75-84.

2. Afrinaldi. Analisa Kinerja Perbankan Syariah Indonesia Ditinjau dari Maqashid Syariah : Pendekatan Syariah Maqashid Index (SMI) dan Profitabilitas bank Syariah. Jurnal Umum Riset Ekonomi dan Keuangan Syariah. 2013;

3. Roza I. Analisis Perbandingan Kinerja Perbankan Syariah dengan Metode Indeks Maqashid Syari'ah dan CAMEL. Tesis Ilmu Ekonomi Islam. Pascasarjana UIN Sunan Kalijaga. Yogyakarta. 2015;

4. Sudrajat A. Syariah Berdasarkan Indeks Maqasid Shari'ah (Studi Kasus pada 9 Bank Umum Syariah di Indonesia Tahun 2015 ). Bisnis. 2016;4(1):178-200.

5. Suhada, Pramono S. Analisis Kinerja Perbankan Syariah Di Indonesia Dengan Pendekatan Maqoshid Indeks (Periode 2009-2011). Akunt dan Keuang Islam. 2014;2(1):22-38.

6. Umiyati U, Faly QP. Pengukuran Kinerja Bank Syariah dengan Metode RGEC. J Akunt Dan Keuang Islam. 2019;3(2):185-201.

7. Mohammed MO. Mohammed, Mustafa Omar. (2008). The Performance Measures of Islamic Banking Based on the Maqashid Framework. IIUM Internasional Accounting Conference (INTAC IV). 2008;(November):1-22. 
8. Abu Zahrah M. Ushul al-Fiqh. Darul Fikri al-Araby. 1958;

9. Marimin, \& Maghfiroh N. Aplikasi Teknik Pengambilan Keputusan dalam Manajemen Rantai Pasok. Bogor: IPB Press. 2010;

10. Omar Mohammed M, Md Taib F. Developing Islamic Banking Performance Measures Based on Maqasid Al-Shari'Ah Framework: Cases of 24 Selected Banks. Vol. 1, Journal of Islamic Monetary Economics and Finance. 2015. p. 55-77.

11. Hakim SA, Al-jubari I, Bhatti OK. Advertising of islamic banking products. Advert Islam Bank Prod. 2011;1(2):60-70.

12. Www.bankmuamalat.co.id diakses 21 Mei 2018. 21 Mei 2018.

13. www.brisyariah.co.id diakses 09 September 2018 [Internet]. 09 September 2018. Available from: www.brisyariah.co.id

14. Www.syariahmandiri.co.id diakses 10 September 2018. 10 September 2018.

15. www.bnisyariah.co.id diakses 10 September 2018. 10 September 2018.

16. www.megasyariah.co.id diakses 10 September 2018. 10 September 2018.

17. www.bcasyariah.co.id diakses 10 September 2018. 10 September 2018. 